\author{
V. SOLODKA ${ }^{1}$, O. OSHAROVSKAYA ${ }^{2}$ \\ Opiekun naukowy: M. PATLAIENKO ${ }^{3}$
}

DOI: https://doi.org/10.53052/9788366249868.22

\title{
FILTRACJA OBRAZÓW SZUMOWYCH W OPARCIU O PRZEKSZTAŁCENIA FALKOWE
}

\begin{abstract}
Streszczenie: Artykuł dotyczy filtrowania obrazów z różnych przeszkód metodami „twardego” $\mathrm{i}$ „miękkiego” zadania funkcji progowej przy filtrowaniu z wykorzystaniem transformacji falkowej. Wprowadzono kryteria ilościowe w celu porównania jakości filtrowania falkowego wykonanego przy użyciu różnych podejść. Zastosowanie filtru falkowego opartego na jednowymiarowym DWT z zakłóceniami jest zlokalizowane i konieczne jest wyeliminowanie go bez zniekształceń sygnału w tych obszarach, w których zakłócenia nie występują. Dlatego do ich korekty można zastosować kryterium amplitudy. Wybierając część współczynników falkowych, które mogą być skorygowane, można kontrolować jakość sygnału informacyjnego.
\end{abstract}

Słowa kluczowe: transformata falkowa, kompresja obrazu, cyfrowe przetwarzanie sygnału, strumień cyfrowy.

\section{FILTRATION OF NOISE IMAGES BASED ON WAVELET TRANSFORMATIONS}

\begin{abstract}
Abstact The article considers the filtering of images from various obstacles, by the methods of "hard" and "soft" task of the threshold function when filtering using wavelet transformation. Quantitative criteria have been introduced to compare the quality of wavelet filtering performed using different approaches. The application of a wavelet filter based on one-dimensional DWT with interference is localized, and it is necessary to eliminate it without signal distortion in those areas in time where interference is absent. Therefore, the amplitude criterion can be used for their correction. By selecting the part of the wavelet coefficients that can be corrected, you can control the quality of the information signal.
\end{abstract}

Keywords: wavelet transform, image compression, digital signal processing, digital stream.

\footnotetext{
1 State University of Intellectual Technologies and Communications, Ukraine, e-mail: valyaonas@gmail.com

2 State University of Intellectual Technologies and Communications, Ukraine, e-mail: osharovskaya@gmail.com

3 State University of Intellectual Technologies and Communications, Ukraine, e-mail: nick_msa@ukr.net
} 


\section{Introduction}

Wavelets are now widely used in image compression tasks; in the processing and synthesis of various signals; when analyzing images of different nature; when convolving (compressing) large amounts of information; to protect information.

Decreasing the absolute values of all wavelet coefficients, including large modulo, can change the amplitude of the recovered signal [1]. For those applications where it is important to keep the amplitude characteristics constant, this approach is not suitable, but there are problems where it is more important to maintain the regularity of the signal than to accurately reproduce its amplitude. An example is the filtering of images from various obstacles, where the method of "soft" task of the threshold function is a widely used approach.

When analyzing signals, the constant amplitude is also not always a mandatory requirement. With regard to image analysis, the procedure of decomposition of wavelet functions involves the transition to a two-dimensional implementation of a discrete wavelet transform, such as two-dimensional DWT. This approach, in particular, is used in computer graphics in the JPEG2000 format. In the practical implementation of this format, the expansion of one-dimensional DWT is considered, in which the rows and columns of the two-dimensional image are analyzed separately. In this case, the image is analyzed horizontally, vertically and diagonally with the same resolution, and the corresponding filters are formed on the basis of the mirror characteristics of the low pass and high pass filters for the one-dimensional case. This procedure is described in more detail, for example, in a review [2]. At each step of decomposition by wavelet levels, the original image is converted into 4 smaller images (1/4 of the input).

\section{Criteria for comparing the quality of wavelet filtering}

To compare the qualities of wavelet filtering, which is performed using different approaches, it is advisable to introduce quantitative criteria. In relation to the signals that are usually entered in the consideration of the root mean square error MSE (1)

$$
E=\frac{1}{N} \sum_{i=1}^{N}[X(i)-Y(i)]^{2}
$$

This value allows you to compare the two signals and quantify the degree of similarity (or, conversely, the degree of difference) between them. If one of the signals is informational (does not contain interference), and the other is a signal received after filtering (and partially contains fluctuations in the case of an imperfect filter), then at each point in time the error is estimated as $e(i)=X(i)-Y(i)$, which is further averaged.

The obtained value $E$ allows us to judge the quality of cleaning the information signal from interference. Note that it does not depend on the temporal or spatial relationships between the samples of the output signal. When analyzing signals or images, the researcher deals with highly structured objects, in particular, the order of the samples reflects the important information characteristics. Distortion (for example, violation of correlations of a certain duration) will affect the quality of the information message, but these distortions may not be reflected in the magnitude $E$. For this reason, for example, when analyzing audio signals containing voice messages, additional 
measures are applied that give a more reliable assessment of quality compared to the root mean square error.

In addition to the root mean square error or the square root of the value (1) in the analysis of the filtering results consider the signal-to-noise ratio (2)

$$
S N R=10 \lg \left(\frac{\sum_{i=1}^{N}[X(i)]^{2}}{\sum_{i=1}^{N}[X(i)-Y(i)]^{2}}\right) .
$$

where $X(i)$ is intput signal containing fluctuations,

$Y(i)$ is the filtered signal, i.e. the evaluation of the signal "cleared" of noise, and, accordingly, the difference in values $|X(i)-Y(i)|$ characterizes the noise component (in the case of an ideal filter) [4-5]. Calculations of quantitative criteria should be performed in addition to visual assessment of filtration quality.

\section{Application of wavelet filter}

The studied signal (Fig. 1a) contains an obstacle (a surface wave of relatively large amplitude, localized in the range [0.25 - 0.5] seconds). It overlaps in the frequency range with the information signal, so for the analysis and adequate interpretation of information about the structure of the earth's crust, it is necessary to solve the problem of filtering the corresponding obstacle. The use of a wavelet filter based on onedimensional DWT is therefore a useful technique, as the interference is localized, and it is necessary to eliminate it without signal distortion in those areas in time where the interference is absent. In contrast to the filtering of high-frequency (and lowamplitude) interference, in this case it is necessary to correct large absolute values of wavelet coefficients [6]. In other words, we apply a different principle - large coefficients (related to the obstacle) are adjusted, and small coefficients remain unchanged. Otherwise, the filtering algorithm remains unchanged.

It is important to note that the task of interference filtering in this example is not to completely eliminate oscillations in the specified time range, but to preserve a useful signal that has a partially overlapping frequency range [7]. When using filtering techniques based on continuous wavelet transform for this purpose, you can perform frequency-time decomposition of the signal. The method used by DWT is less obvious, but at the same time has much less redundancy and higher speed.

After applying one-dimensional DWT with Daubechiesi wavelet $D^{8}$ to the signal given in (Fig. 1a), a set of wavelet coefficients was obtained (Fig. 1b), which contains both useful geophysical information and information about the obstacle. During the analysis of the corresponding set of wavelet coefficients authors, it was found that the wavelet coefficients containing information about the noise are preferably in the range $n=[30,70]$ and have a large amplitude. Therefore, the amplitude criterion can be used for their correction [8].

Resetting all wavelet coefficients in the range $n=[30,70]$ reduces the interference (Fig. 2a). In this case, only the oscillations in the time range [0.25 - 0.5] s are corrected, and the information signal outside this range remains undistorted. By selecting the part of the wavelet coefficients that can be corrected, you can control the 
quality of the information signal. Presented in (Fig. 2a), the filtering results were obtained for the case when the wavelet coefficients are corrected only at the 1 st level of resolution. By analogy, you can correct the coefficients at higher levels of resolution (Fig. 2b), which reduces the amplitude of oscillations in the already mentioned time range. The obvious disadvantage of this method of wavelet filtering is the distortion of the information signal.

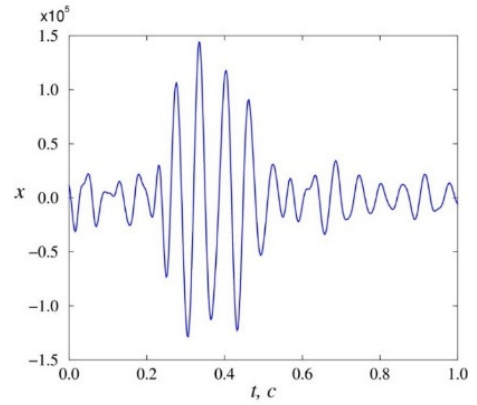

a)

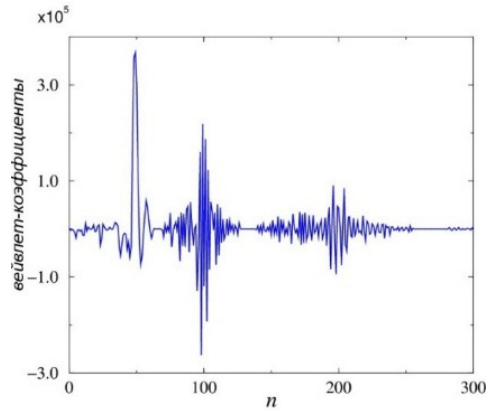

b)

Figure 1. Fragment of the image string containing noise (a) and the corresponding set of wavelet coefficients $(b)$

They are associated both with the use of wavelets with a relatively small area of the task (not enough smooth functions), and with the choice of rules for the correction of coefficients. Various techniques can be used to reduce signal reconstruction errors. One of the problems is the presence of gaps in the transition from the area of the corrected wavelet coefficient to the area where the wavelet coefficients remain undistorted (by analogy with the rigid task of the threshold function, but with the difference that the corrections are subject to coefficients exceeding the threshold ).

\section{Application of the threshold function}

To eliminate such gaps can be used a technique that consists in the application of a smoother threshold function.

As can be seen from Fig. 3, the application of the threshold function reduces the distortion of the recovered signal. These conclusions have been drawn for numerous examples of noisy data. In all examples, the smoothing of the threshold function improved the quality of signal reconstruction. The effective value of the filtering error when using the function was significantly less than for the hard version, and approximately $0.5 \%-1 \%$ less than for the soft version. Thus, the advantage of smoothing the threshold function to reduce the error is confirmed. However, because the soft version is the standard option, which provides comparable accuracy and some advantage in terms of computational speed, we mainly used it in signal filtering problems in the communication channel. 


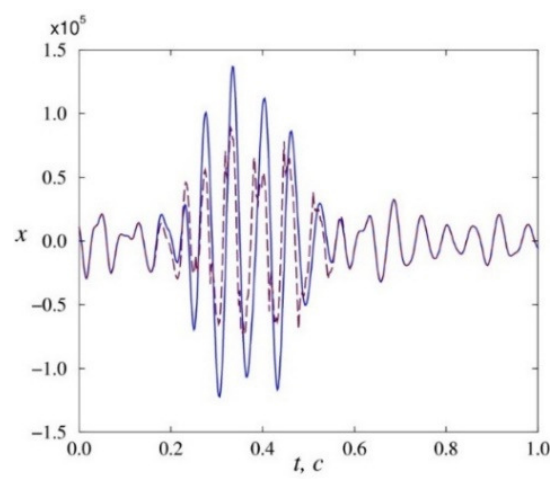

a)

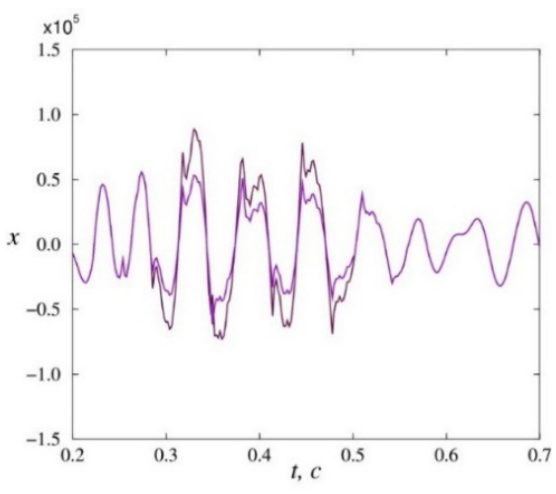

b)

Figure 2. Signal before and after filtering when correcting wavelet coefficients only at the 1st level of resolution (a) and at all levels of resolution (b) (hard version of the threshold function). In the latter case, there is a smaller amplitude of oscillations in the presence of the obstacle

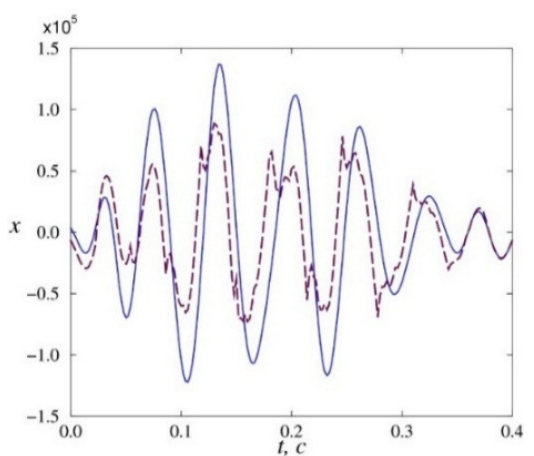

a)

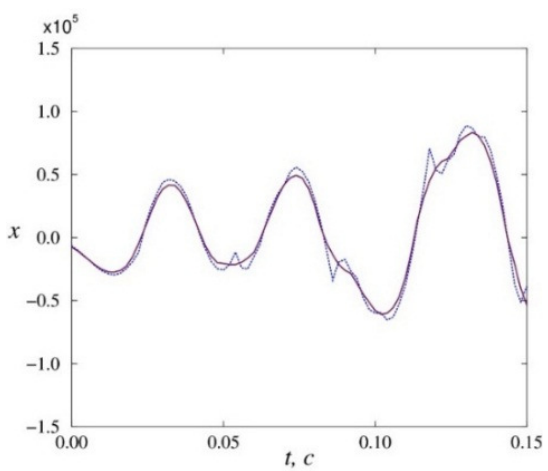

b)

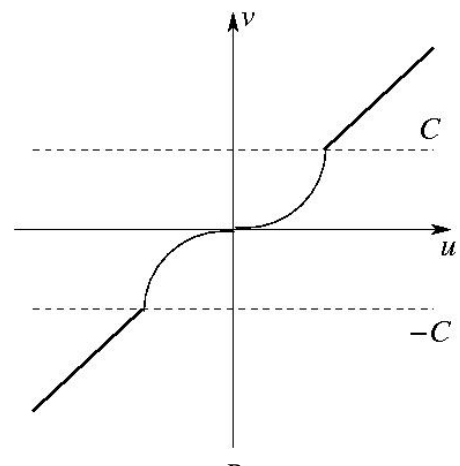

B

Figure 3. Signal distortion after filtering (a) and transition to a smoother time function $(b)$ in the case of using the threshold function $(c)$ when correcting wavelet coefficients 
When eliminating large-amplitude interference, it is often difficult to assess the quality of the filtering, as quantitative criteria (1) and (2) are inappropriate. In addition, the appropriate filtering can and should be carried out in conjunction with experts in the relevant field, who can on the basis of visual analysis of the processed data to conclude on the effectiveness of the purification of the information signal. For this reason, we will consider the problem of wavelet filtering of signals containing high-frequency and low-amplitude interference, after which you can estimate the filtering error. A useful technique at the stage of testing wavelet filtering methods is to mix noise with known statistical characteristics into the information signal with its subsequent filtering. In this case, the use of a priori information allows you to compare the effectiveness of different methods of cleaning the signal from noise.

If noise is added that has statistics close to the interference contained in the recorded signal, then pre-setting the filter parameters will improve the quality of wavelet filtering.

It is important to note that the settings of wavelet filters depend on the level of interference, and this fact must be taken into account when automating the threshold filtering process.

Examples of filtering experimental data using Daubechiesi wavelet $D^{10}$ for cases of soft and hard task of the threshold function are presented in Fig. 3. Some fragments of the time dependence shown in Fig. 3, allow us to judge that the rigid task of the threshold function leads to a stronger distortion of the information signal. Calculations of the root mean square filtering error confirm this conclusion. Accordingly, in the soft version of the threshold function there is a decrease in the error of signal recovery by its wavelet coefficients by about $8 \%$ compared to the hard version (this value depends on the noise level and increases with increasing intensity of the present interference).

Table 1. Error values for different values of noise intensity and two ways to set the threshold function

\begin{tabular}{|l|l|l|l|l|}
\hline $\begin{array}{c}\text { Noise } \\
\text { variance }\end{array}$ & $\begin{array}{c}\text { Optimal } \\
\text { threshold } \\
\text { level (rigid } \\
\text { threshold } \\
\text { function) }\end{array}$ & Error R & $\begin{array}{c}\text { Optimal } \\
\text { threshold } \\
\text { level (soft } \\
\text { task of } \\
\text { threshold } \\
\text { function) }\end{array}$ & $\begin{array}{c}\text { Noise } \\
\text { variance }\end{array}$ \\
\hline 0.1 & 0.134 & 0.1048 & 0.1085 & 0.303 \\
\hline 0.2 & 0.13 & 0.1864 & 0.1884 & 0.305 \\
\hline 0.3 & 0.118 & 0.2681 & 0.2695 & 0.284 \\
\hline 0.4 & 0.1 & 0.3418 & 0.3429 & 0.258 \\
\hline 0.5 & 0.083 & 0.4023 & 0.4031 & 0.236 \\
\hline
\end{tabular}

Another important point to pay attention to. The minimum error dependence of the value of $\mathrm{C}$ for the soft variant is achieved at lower values of $\mathrm{C}$. Since this value sets a threshold for wavelet coefficients that can be reset when filtering interference, decreasing $\mathrm{C}$ means that less informative coefficients will be eliminated at the filtering stage. As a result, the probability of removing the coefficients that characterize the useful signal is reduced, and, as a consequence, the probability of introducing random 
distortions (or the risk of threshold filtering according to commonly used terminology) is reduced.

This conclusion is confirmed by additional calculations performed at different signalto-noise ratios. In all cases, a mild version of the threshold function reduces the risk of threshold filtration
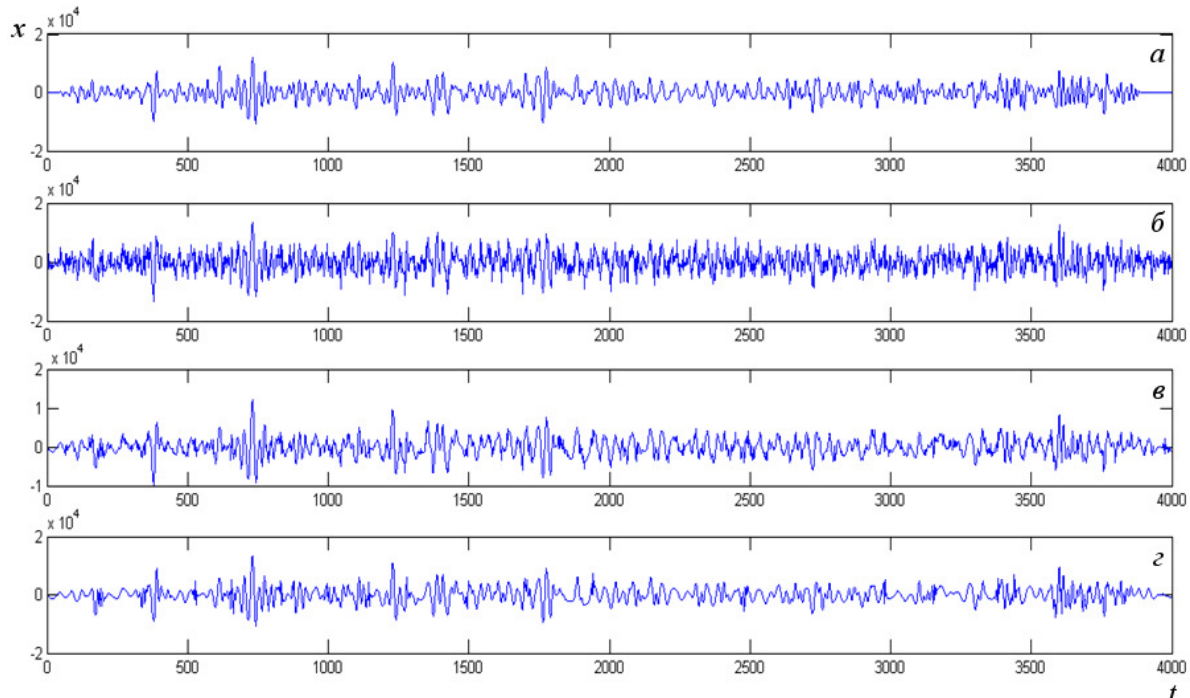

Figure 4. Examples of wavelet filtering image timing: (a) - output signal, (b) - signal with added interference (white noise), signal-to-noise ratio $1 \mathrm{~dB},(\mathrm{c})$ - filtering using

Daubechies wavelet $D^{10}$ and soft variant of the threshold function, (d) - filtering using the Daubechiesa wavelet $D^{10}$ and the rigid variant of the threshold function.

When the level of interference decreases, the optimal values of $\mathrm{C}$ converge and go to zero at very low noise levels. The obtained results were further compared with the results of the analysis of other examples of noisy signals in order to establish and confirm the general patterns observed in wavelet filtering of experimental data. This comparison allowed us to confirm the observed patterns. In both examples, it is confirmed that the soft version of the task of the threshold function provides less error compared to the hard version of the corresponding task of the threshold level. In addition, the optimum for the soft task of the threshold function is achieved at a lower value of $\mathrm{C}$, which reduces the risk of threshold filtration.

Thus, an important task is the choice of parameter $\mathrm{C}$, which should be carried out taking into account the noise level in the analyzed experimental data. Among the widely used methods of selection $C(3)$ is the universal threshold level proposed in [8].

$$
C=\sigma \sqrt{2 \ln N}
$$

where $\sigma$ is a standard noise deviation,

$N$ is number of wavelet coefficients $(N \geq 4)$

When performing a discrete wavelet transform, the number of coefficients changes 2 times when moving from one resolution level to another. For this reason, both 
approaches based on global threshold input ( $C$ is a fixed value that does not depend on the resolution level) and more flexible approaches that involve setting different threshold levels $C j$ depending on the resolution $\mathrm{j}$ can be used.

The following value is used as an estimate (4)

$$
\frac{M\left(\left|d_{J-1, k}-M\left(d_{J-1, k}\right)\right|\right)}{0.6745},
$$

where $M$ is a median,

$J$ is the maximum level of resolution when implementing one-dimensional DWT.

The choice of the previous level $J-1$ is due to the fact that at this level the wavelet coefficients are mainly related to noise. As a quantitative criterion is often used to estimate the probability of signal distortion during threshold filtering or filtering error [9], to reduce which it is advisable to use methods that use minimum threshold values that lead to less significant signal distortion.

For this purpose, an alternative to the threshold task is widely used - the SURE method [10]. According to this method, as an estimate of the threshold level is considered the value of (5)

$$
\begin{aligned}
& \hat{C}=\arg \min _{C} \sum_{m=0}^{N-1} P\left(D_{m}\right), \\
& P\left(D_{m}\right)= \begin{cases}D_{m}^{2}-\sigma^{2}, & D_{m} \leq C \\
\sigma^{2}+C^{2}, & D_{m}>C\end{cases}
\end{aligned}
$$

According to research, the values $\hat{C}$ are close to the optimal threshold level. However, this approach can also lead to errors at high noise intensities. In such situations, it is better to share the universal threshold level and the SURE method: if the wavelet coefficients are small, then the first approach is used, and otherwise - the second. To determine the choice of method, the minimum energy level $\varepsilon_{N}=\sigma^{2} N^{1 / 2}(\ln N)^{3 / 2}$ is set, and the threshold value is determined as follows (6)

$$
C=\left\{\begin{array}{ll}
\sigma \sqrt{2 \ln N}, & \left\|D_{m}\right\|^{2}-N \sigma^{2} \leq \varepsilon_{N} \\
\hat{C}, & \left\|D_{m}\right\|^{2}-N \sigma^{2}>\varepsilon_{N}
\end{array} .\right.
$$

According to the results, the approach based on the problem of the universal threshold level leads to the largest standard error. The SURE method provided the minimum error of the three approaches considered.

\section{Conclusion}

Various techniques can be used to reduce signal reconstruction errors. One of the problems is the presence of gaps in the transition from the area of the corrected wavelet coefficient to the area where the wavelet coefficients remain undistorted (by analogy with the rigid task of the threshold function, but with the difference that the corrections are subject to coefficients exceeding the threshold). The use of a threshold function reduces the distortion of the recovered signal. These conclusions have been 
drawn for numerous examples of noisy data. In all examples, the smoothing of the threshold function improved the quality of signal reconstruction. The effective value of the filtering error when using the function was significantly less than for the hard version, and approximately $0.5 \%-1 \%$ less than for the soft version. Thus, the advantage of smoothing the threshold function to reduce the error is confirmed. However, because the soft version is the standard option, which provides comparable accuracy and some advantage in terms of computational speed, we mainly used it in signal filtering problems in the communication channel.

When eliminating large-amplitude interference, it is often difficult to assess the quality of the filtering, as quantitative criteria (1) and (2) are inappropriate. In addition, the appropriate filtering can and should be carried out in conjunction with experts in the relevant field, who can on the basis of visual analysis of the processed data to conclude on the effectiveness of the purification of the information signal. For this reason, we will consider the problem of wavelet filtering of signals containing high-frequency and low-amplitude interference, after which you can estimate the filtering error. A useful technique at the stage of testing wavelet filtering methods is to mix noise with known statistical characteristics into the information signal with its subsequent filtering. In this case, the use of a priori information allows you to compare the effectiveness of different methods of cleaning the signal from noise.

Accordingly, in the soft version of the threshold function there is a decrease in the error of signal recovery by its wavelet coefficients by about $8 \%$ compared to the hard version (this value depends on the noise level and increases with increasing intensity of the present interference).

\section{REFERENCES}

1. ЭЙНШТЕЙНА А.: Теория наблюдаемых искажений. Часть І. Новый взгляд на специальную теорию относительности А. Эйнштейна http: //theory.moy.su/publ/3-1-0-17.

2. УЭЛСТИД С.: Фракталы и вейвлеты для сжатия изображений в действии // М.: Издательство Триумф 2003. - 320 с

3. АСТАФЬЕВА Н.М.: Вейвлет-анализ: основы теории и примеры применения// Успехи физических наук, т. 166, №11, 1996.с.

4. ГОНСАЛЕС Р., ВУДС Р.: Цифровая обработка изображений. М.: Техно cфера, 2005. - 1072 c.

5. ОППЕНГЕЙМ А.: Цифровая обработка сигналов / А. Оппенгейм, Р. Шафер. - М.: Техносфера, 2007

6. GROSSMAN A.: Decomposition of Hardy functions into square integrable wavelets of constant shape / A. Grossman, J. Morlet // SIAM J. Math. Anal. 1984. - Vol. 15. - P. 723-736.

7. DAUBECHIES I., LAGARIAS J.: Two-scale difference equations. Global regularity of solutions // Society for Industrial and Applied Mathematics. - 1991. - P. 1388-1410.

8. ЯКОВЛЕВ А. Н.: Введение в вейвлет-преобразования. - Новосибирск, Россия: НГТУ, 2003. - 104 с.

9. PATLAENKO M.A., V. OSHAROVSKA O., SAMUS N.S.: Adaptive shake of thresholds for quantizing wavelet coefficients, Vimiryuvalna and numerical 
technology in technological processes (VOTTP-16-2016). Materials of the 16th International Scientific and Technical Conference, 10 - 15 June 2016: abstracts of reports. Odessa. 2016. P. 173.

10. PATLAYENKO M., OSHAROVSKA O., PYLIAVSKYI V., SOLODKA V.: Wavelet Feature Family for Image Compression. 27-th National conference "Telecom 2019", 30-31 October 2019, National science and Technical Center, Sofia, Bulgaria, P.15-18. 